Jurnal Abdimas Berdaya : Jurnal Pembelajaran, Pemberdayaan dan Pengabdian Masyarakat Volume 4 Nomor 02 Tahun 2021

P-ISSN: $2685-1563$ e-ISSN: 2720 - 9768

\title{
Pengolahan Kopi Excelsa Pasca Panen Terhadap Roasting Kopi di Kelurahan Pecalukan Kecamatan Prigen Kabupaten Pasuruan
}

\section{The Appearance of Excelsa Coffee as a Result of Exploration in Pecalukan Village, Prigen District, Pasuruan Regency}

\author{
Muhammad Imron Rosadi'), Abdul Majid'2), Abi Rizal ${ }^{3)}$, Bahrul Ulum ${ }^{4}$, \\ Khozinul Asror' ${ }^{5)}$ Muhammad Fu'ad ${ }^{6)}$, Didit Proyogi ${ }^{7)}$, Yuyud Akhmad Dhani ${ }^{8)}$ \\ 1,3,4,5,6,7,8 Universitas Yudharta Pasuruan \\ ${ }^{2}$ Universitas Muhammadiyah Lamongan \\ e-mail: imron.rosadi@yudharta.ac.id ${ }^{1}$, abdulmajid@umla.ac.id ${ }^{2)}$, \\ Wandenkndenk@gmail.com ${ }^{3)}$, Bahroel718@gmail.com ${ }^{4}$, Samalwi12@gmail.com ${ }^{5}$ \\ Muhammadfuad2802@gmail.com ${ }^{6}$, Diditprayogi97@gmail.com ${ }^{7)}$, Yuyud.d4@gmail.com ${ }^{8}$
}

Abstrak: Penampilan kopi excelsa hasil eksplorasi di Kelurahan Pecalukan Kecamatan Prigen Kabupaten Pasuruan.. Kopi excelsa merupakan salah satu jenis kopi yang dibudidayakan di Indonesia, tanaman ini merupakan introduksi untuk ditanam di dataran rendah, produksi kopi excelsa rendah dan cita rasanya asam sehingga kurang disukai. Secara morfologi kopi excelsa mempunyai kemiripan sifat dengan kopi liberika. Kopi excelsa dapat digunakan sebagai batang bawah karena mempunyai sifat perakaran yang kuat, tahan terhadap nematoda dan lahan gambut. Kegiatan eksplorasi dilaksanakan di Kelurahan Pecalukan Kecamatan Prigen Kabupaten Pasuruan pada bulan Juli s/d Agustus 2020. Eksplorasi dilakukan dalam bentuk wawancara langsung dengan petani. Metode pengambilan contoh dan data dilakukan secara acak (random). Masing-masing sampel diamati karakter bijinya meliputi warna, bau, dan bentuk biji. Tujuan penelitian adalah untuk mengetahui pengaruh perbedaan proses pasca panen pada kopi excelsa di Kelurahan Pecalukan Kecamatan Prigen Kabupaten Pasuruan. Hasil eksplorasi menunjukkan bahwa proses pasca panen kopi excelsa memiliki pengaruh yang signifikan terhadap karakter rasa.

Kata Kunci: Pelatihan, Kopi Excelsa, Pasca Panen, Petani Kopi

Abstract: Excelsa coffee is one type of coffee that is cultivated in Indonesia, this plant is an introduction to be planted in the lowlands, excelsa coffee production is low and the taste is sour so it is not preferred for some people. Morphologically, excelsa coffee has similar characteristics with liberica coffee. Excelsa coffee can be used as rootstock because it has strong roots also resistant to nematodes and peatlands. The exploration activities were carried out in Pecalukan Village, Prigen District, Pasuruan Regency from July to August 2020. Exploration was carried out in the form of direct interviews with farmers of Pecalukan village. The sampling method and data were carried out randomly. Each sample was observed for the characteristics of the seeds including color, odor, and shape of the seeds. This study aims to determine the effect of differences in post-harvest processing on excelsa coffee in Pecalukan Village, Prigen District, Pasuruan Regency. The results of the exploration showed that the post-harvest process of excelsa coffee had a significant effect on the character of the taste.

Keywords: Training, Excelsa Coffee, Post Harvest, Coffee Farmers 


\section{A. Pendahuluan}

Kopi excelsa merupakan salah satu jenis kopi yang dibudidayakan di Indonesia. Yahmadi (1972) menyatakan bahwa kopi excelsa merupakan tanaman introduksi untuk ditanam di dataran rendah, produksi kopi excelsa rendah dan cita rasanya asam sehingga kurang disukai. Secara morfologi kopi excelsa mempunyai kemiripan sifat dengan kopi Liberika. Baon (2011) menyatakan bahwa kopi excelsa dapat digunakan sebagai batang bawah karena mempunyai sifat perakaran yang kuat, tahan terhadap nematoda dan lahan gambut.

Kopi excelsa ditemukan pertama kali pada tahun 1905 oleh August Chevailer, seorang botani asal Perancis. Dia menggunakan kopi ini disekitar aliran Sungai Chari tidak jauh dari tidak jauh dari Danau Chad di Afrika Barat. Mulanya tanaman ini disebut coffea excels kadang-kadang juga disebut dengan coffea dewevrei.

Dikemudain hari kopi ini tidak dianggap spesies tersendiri melainkan digolongkan sebagai kopi liberika dengan nama ilmiah Coffea liberica var dewevrei. Hingga saat ini klasifikasi dan nama iliah kopi excelsa masih diperdebatkan, tak heran jika kopi ini memliki banyak sinonim.

Kopi excelsa tidak banyak diperdagangkan, dimana lebih banyak dari 90\% kopi dunia didominasi jenis arabika dan robusta. Sehingga budidayanya juga dilakukan secara terbatas.

Kopi excelsa (Coffea liberica var. dewevrei) secara taksonomi tergolong dalam sub-seksi Pachycoffea, satu kelompok dengan kopi Liberika (Coffea liberica Bull ex Hiern) dan masuk dalam kelompok Liberoid, namun berbeda kelompok dengan kopi Arabika (Arabikoid) maupun kelompok kopi Robusta (Robustoid) (Dinas Perkebunan Provinsi Jambi dan Puslitkoka 2013).(UDARNO 2015)

Tanaman kopi excelsa cocok dikembangkan pada ketinggian lahan sekitan 0-750 Mdpl. Idealnya ditanam di daerah beriklim tropis dengan curah hujan sedang. Pada tingkat curah hujan tinggi tanaman ini akan lebih mengembangkan batangnya dibanding buahnya. Untuk bisa berbunga excelsa memerlukan waktu satu hingga dua bulan dengan curah hujan dalam setahun. Tanaman ini diketahui tahan terhadap penyakit karat daun, Hemielia vastratrix (HV).

Di Indonesia kopi excelsa dibudidayakan secara terbatas karna Tanaman ini bisa tumbuh di tanah gambut yang memiliki tingkat keasaman yang tinggi. Kopi excelsa termasuk tanaman kopi yang cepat menghasilkan, dalam kurun 3,5 tahun buahnya sudah bisa dipanen.

Kopi Excelsa juga merupakan salah satu kopi khas Kelurahan Pecalukan Kec.Prigen.jenis kopi ini tumbuh dengan baik \& lumayan subur di sekitaran lereng welirang \& arjuno, bahkan kopi jenis ini juga menjadi produk unggulan kelurahan Pecalukan.kopi exselsa sendiri memang bisa dikatakan jenis kopi yang premium/limited edition karna mengingat kopi jenis ini memang tidak bisa tumbuh di tempat sembarangan ,dan populer dengan sebutan kopi nangka di sekitaran kelurahan pecalukan, sejak lama kopi excelsa sudah dikenal banyak orang dan utamanya para 
pecinta kopi yang penasaran dengan kopi jenis ini, namun sering kali kualitas rasa yang didapat konsumen cenderung biasa dan tidak menonjolkan rasa kopi exselsa/kopi nangka yang sesungguhnya dan Setelah ditelisik hal tersebut adalah karena berbagai proses yang dilakukan pada kopi memang sangatlah banyak dan berbeda-beda, mulai dari penanaman, pengeringan, pembakaran (Roasting), dan proses peracikan, yang paling penting yaitu proses paska panen pada kopi sendiri sangat berpengaruh besar pada rasa yang akan kita tonjolkan dari kopi itu sendiri.dan Pada kesempatan kali ini kami akan membahas pada proses pengeringan dan pembakaran (Roasting) karena dalam proses inilah yang paling mempengaruhi cita rasa kopi.

Tujuan dari pengabdian ini adalah agar para pengusaha kopi dapat menciptakan karya cita rasa kopi sesuai dengan keinginan mereka dengan menggunakan metode pengeringan dan pembakaran (Roasting) yang tepat.

\section{B. Metode}

Pengabdian ini dilakukan pada tanggal 15 Juli - 8 Agustus 2020 di UMKM Karang Taruna Sentana Kelurahan Pecalukan Kecamatan Prigen Kabupaten Pasuruan. Metode yang dipakai dalam pengabidan ini adalah PAR (participation action reseach). Karena dalam pengabidan ini kita melakukan pendampingan langsung dengan mitra. Eksplorasi dilakukan dengan cara observasi deskriptif non-eksperimen dengan cara pengumpulan data lapangan melalui pengamatan jenis kopi yang ada dilokasi, wawancara terkait pe roastingan atau pengolahan biji kopi Excelsa Pasca Panen

\section{Hasil dan Pembahasan}

Untuk mencapai tujuan kami, kami melakukan beberapa hal dengan pihak UMKM Karang Taruna Sentana:

1. Melakukan observasi dan survei secara langsung pada tempat pemrosesan kopi.

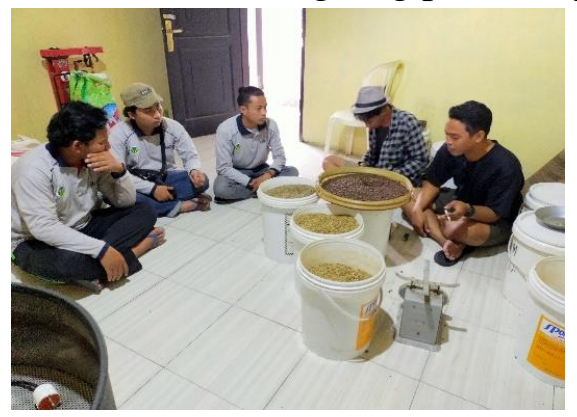

Gambar 1: Observasi dan Wawancara

Dalam pelaksanaannya peneliti mendatangi langsung tempat pemrosesan kopi mulai dari pengeringan sampai roasting. Disana peneliti mengumpulkan data-data serta mengamati langsung setiap proses yang dilakukan terkait setiap perbedaan proses dan hasilnya. 
2. Melakukan wawancara kepada Pengurus Karang Taruna dan anggota dari Devisi Ekonomi Kreatif Karang Taruna Sentana serta pengelola yang langsung turun ke lapangan.

Selain melakukan observasi dan survei secara langsung ke tempat pengolahan kopi, peneliti juga melakukan wawancara terkait pengolahan dari setiap prosesprosenya. Yang nantinya dari hasil wawancara dari beberapa sumber ini diakumulasikan dengan hasil survei dan observasi untuk mendukung keautentikan data yang telah peneliti dapat sebelumnya.

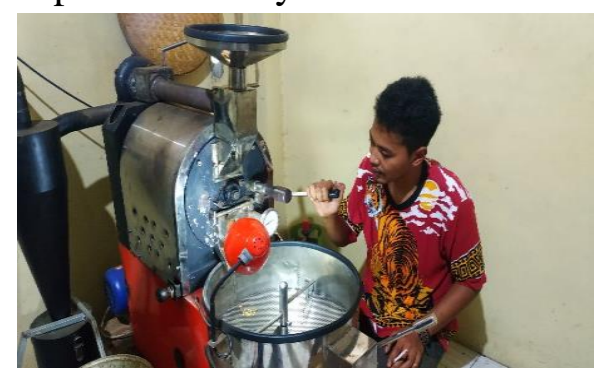

Gambar 2: Proses Roasting Kopi

3. Melakukan diskusi secara terus-menerus baik dalam intra peneliti dan extra atau dalam hal ini dengan pihak Karang Taruna Sentana.

Untuk mendapatkan suatu hasil dari pemrosesan kopi yang baik dan yang natinya akan dibuat sebuah acuan dalam pemrosesan kopi Excelsa pasca panen, peneliti melakukan diskusi secara terus-menerus baik dalam internal peneliti juga dengan pihak-pihak terkait yang dalam hal ini adalah Pihak Karang Taruna Sentana yang mana di dalamnya juga terdapat para pegiat kopi dan pengolah kopi. Dari hasil diskusi yang terus menerus inilah dicetuskan sebuah acuan dalam pemrosesan kopi Excelsa yang baik di Kelurahan Pecalukan khususnya pada Devisi Ekonomi Kreatif di Karang Taruna Sentan Kelurahan Pecalukan.

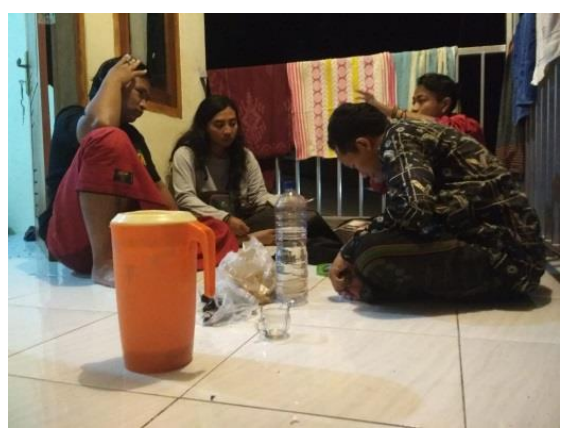

Gambar 3: Diskusi secara Continue

4. Mensosialisasikan hasil penelitian kepada Pengurus Karang Taruna yang nantinya hasil penelitian ini bisa digunakan sebagai acuan dalam pengolahan kopi pasca panen. 


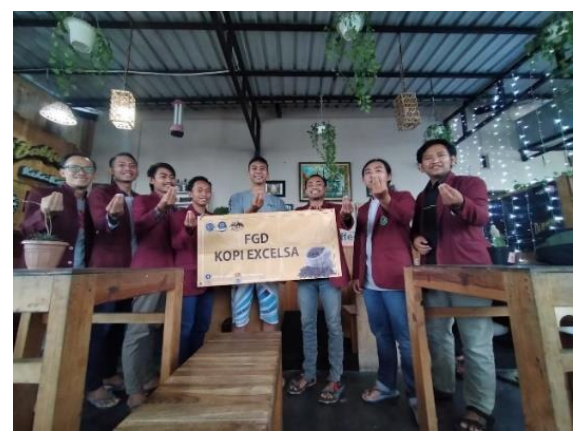

Gambar 4: FGD Kopi Excelsa

Dari hasil penelitian yang cukup panjang dan dirumuskan dalam diskusi-diskusi yang dilakukan secara terus menerus, muncullah sebuah acuan cara pemrosesan kopi yang dianggap paling baik. Untuk mencapai tujuan peneliti dalam hal ini: Pemberdayaan Ekonomi Masyarakat Petani Kopi Excelsa Melalui Pelatikan Pengolahan Kopi Excelsa.

Prigen Kabupaten Pasuruan" maka peneliti mengadakan Forum Group Discussion (FGD) dengan Pengurus Karang Taruna Sentana Kelurahan Pecalukan, yang nantinya hasil penilitian ini bisa dibuat acuan oleh Pengurus Karang Taruna dalam pemrosesan kopi excelsa yang baik dan bisa disosialisasikan kepada seluruh anggota khususnya dan Mayarakat petani kopi Excelsa Kelurahan Pecalukan Pada Umumnya.

Berikut ini adalah tahapan yang perlu diperhatikan dalam proses Roasting :

1. Pastikan Green Bean kopi yang akan dirosting berada pada tingkat kadar air $11 \%$ dan setelah proses Roasting kadar air tersisa menjadi $4 \%$.

2. Kenali kopi yang akan di Roasting dan rancang atau tentukan rasa terbaik kopi yang bisa dihasilkan oleh Green Bean tersebut.

3. Lakukan pemanggangan Green Bean sampai kopi berubah warna secara bertahap, dari hijau menjadi kuning, lalu kuning kecoklatan, terus coklat muda, coklat tua, coklat kehitaman sampai menjadi kehitaman sampai yang terakhir menjadi hitam.

4. Lakukan pemanggangan dengan menggunakan 3 tipe dasar pemanggangan yang bergantung pada warna kopi, suhu Roasting, dan waktu selama Roasting berlangsung.(Thomas Edvan et al. 2016)

Tingkatan pemanggangan paling umum dijadikan patokan terutama di Indonesia ada tiga tingkat yaitu : Light Roast, Medium Roast, dan Dark Roast.

1. Light Roast (Coklat Muda)

Roasting pada tingkat ini rasa kopi memiliki cita rasa asam, aroma sangrai kurang tercium, tahapan pertama biji kopi yang telah disangrai beberapa menit akan sedikit mengembang. Fase ini juga merupakan fase roasting yang memiliki tingkat kematangann paling rendah. Warna kopi akan sedikit coklat terang karna proses penyerapan panas yang dilakukan tidak terlalu lama, juga tidak muncul minyak pada kopi dan biji kopi cenderung kering. Light roast memiliki suhu biji kopi berada pada kisaran 180 - 200 derajat celcius. Pada proses ini terjadi first crack dan 
pada saat itu pula proses roasting dihentikan. Kopi yang di roasting pada tingkatan ini memiliki keasaman dan caffeine yang tinggi. Proses ini cocok bagi pecinta rasa kopi yang mencolok, karena memiliki ciri khas tersendiri.

2. Medium Roast

Roasting pada tingkat ini kopi memiliki cita rasa manis dan aroma asap penyaringan sangat tajam tercium, karena biji kopi banyak mengeluarkan asap, warnanya makin hitam sampai berminyak dan kandungan gula mulai berkarbonisasi. Medium roasting merupakan tingkatan roasting yang paling banyak digunakan. Medium roast memiliki suhu biji kopi pada kisaran 210 - 220 derajat celcius. Pada suhu tersebut adalah suhu dimana first crack usai namun second crack belum terjadi. Selain caffeine yang lebih rendah, medium roast menghasilkan kopi yang cenderung balance aroma, kesamaan dan menghasilkan banyak rasa.(R, Puspitasari, and Arvianto 2015)

3. Dark Roast

Merupakan tingkatan paling matang pada proses roasting kopi, namun jika proses roasting melebihi tingkatan ini akan membuat rasa kopi tidak enak. Warna biji kopi akan lebih gelap bila dibandingkan tingkatan roasting lainnya. Pada tingkatan ini biji kopi hasil roasting mengeluarkan minyak pada permukaannya. Rasa kopi juga cenderung pahit dan menutupi rasa khas dari masing-masing kopi. Dark roast selesai diroasting setelah second crack usai. Kopi hasil roastingan ini cocok untuk yang menyukai kopi kental dan kopi yang tebal

\section{Simpulan}

Program Pemberdayaan Masyarakat ini telah berhasil dilaksanakan, pendampingan dilakukan selama kurang lebih 1 Bulan. Hasil dari program ini secara umum adalah kemampuan untuk mengolah kopi pasca panen pada UMKM Karang Taruna Sentana meningkat dan sesuai dengan proses sesungguhnya sehingga menciptakan aroma kopi yang bagus dan harga bersaing yang bermerk Excelsa. Karena program yang dilaksanakan merupakan program berkelanjutan, maka Karang Taruna Sentana Kelurahan Pecalukan dapat terus melakukan konsultasi kepada tim.

\section{Saran}

Kegiatan ini nanti berkelanjutan sampai bagaimana proses pemasaran produk kopi excels dan proses penjemuran kopi dengan teknik Doom dan Drying Beds. 


\section{Daftar Rujukan}

Putra, Hayuangga Tino. 2018. "BERDASARKAN HASIL ROASTING MENGGUNAKAN ALGORITMA FUZZY C - MEANS SKRIPSI Oleh: HAYUANGGA TINNO PUTRA KUSUMA JURUSAN TEKNIK INFORMATIKA."

R, Arya Anantama, Nia Budi Puspitasari, and Ary Arvianto. 2015. "Menentukan Kombinasi Optimal Parameter Coffee Roasting Untuk Mendapatkan Roasted Bean Dengan Tingkat Kematangan Medium Roast Menggunakan Metode Taguchi." J@Ti Undip: Jurnal Teknik Industri 10 (3): 163-68. https://doi.org/10.12777/jati.10.3.163-168.

Rachmawati, Mega. 2016. "Penyutradaraan Dokumenter Laporan Taste of Coffee." Thesis (Skripsi) Bab I-VI: 1-92. http://digilib.isi.ac.id/id/eprint/2037.

Thomas Edvan, Bukhori, Rachmad Edison, dan Made Same, Mahasiswa Jurusan Budidaya Tanaman Perkebunan dan, and Staf Pengajar Jurusan Budidaya. 2016. "Pengaruh Suhu Dan Lama Penyangraian Pada" 4 (1): 31-40.

UDARNO, M. LABA. 2015. "Penampilan Kopi Excelsa Hasil Eksplorasi Di Kabupaten Kepulauan Meranti, Riau” 1: 543-47. https://doi.org/10.13057/psnmbi/m010328 